\title{
Improving the safety of CAR-T cell therapy by controlling CRS-related coagulopathy
}

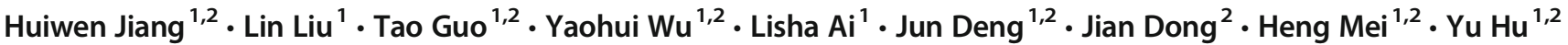

Received: 2 September 2018 / Accepted: 6 April 2019 / Published online: 4 May 2019

(C) Springer-Verlag GmbH Germany, part of Springer Nature 2019

\begin{abstract}
The CD19-targeted chimeric antigen receptor T cell (CAR-T) therapy has been widely proved effective on relapsed and refractory $(\mathrm{r} / \mathrm{r}) \mathrm{B}$ cell acute lymphoblastic leukemia (B-ALL). Meanwhile, CAR-T therapy-related toxicities, including cytokine release syndrome (CRS) and neurological toxicities, are drawing researchers' attention. In addition, our research team notices that coagulopathy and even disseminated intravascular coagulation (DIC) are common problems during CAR-T therapy. In our phase 1/2 clinical trial (NCT02965092), $53 \mathrm{r} / \mathrm{r}$ B-ALL patients underwent leukapheresis on day - 11 and received lymphodepleting chemotherapy on day -7 to day -5 . Finally, they received split infusions of anti-CD19 CAR-T cells on day 0 to day 2. Plasma concentrations of tissue factor (TF) and platelet endothelial cell adhesion molecular-1 (PECAM-1) were also measured to identify the mechanism of coagulation disorders. The overall 1-month remission rate of the 53 patients was $88.7 \%$. During the treatment course, 19 patients experienced grade 3-4 CRS, 8 patients developed grade 2-3 neurological toxicities. Beyond that, 30 patients $(30 / 53,56.6 \%)$ suffered from coagulation disorders, and half of them should be diagnosed as DIC. Benefiting from replacement and anticoagulant therapy, 14 patients successfully got out of the conditions of DIC. Remarkably, the severity of coagulopathy was positively correlated with CRS grade. What is more, plasma TF and PECAM-1 levels indicated that vascular endothelial factors played key roles in the process of CRS-related coagulopathy. To conclude, coagulation disorders frequently happen during CAR-T therapy. TF and PECAM-1 are of great importance in the etiology and pathogenesis of coagulation problems. Early and proper interventions targeted at CRS-related coagulopathy contribute a lot to the control of side effects in CAR-T therapy.
\end{abstract}

Keywords Chimeric antigen receptor-T therapy $\cdot$ Coagulation $\cdot$ Cytokine release syndrome $\cdot$ Tissue factor $\cdot$ Plateletendothelial cell adhesion molecular-1

\section{Introduction}

Numerous preclinical experiments and clinical trials have accelerated the development process of chimeric antigen receptor-modified T cell (CAR-T) therapy and demonstrated that CAR-T therapy had considerable promise against

Heng Mei

hmei@hust.edu.cn

$\mathrm{Yu} \mathrm{Hu}$

dr_huyu@126.com

1 Institute of Hematology, Union Hospital, Tongji Medical College, Huazhong University of Science and Technology, Wuhan 430022, China

2 Hubei Clinical Medical Center of Cell Therapy for Neoplastic Disease, Wuhan 430022, China malignant diseases, especially hematological malignancies. In CD19-positive B cell malignancies, approximately 90\% acute lymphoblastic leukemia (ALL) patients [1-12] and 70\% lymphoma patients [13-18] can get remissions through CD19-specific CAR-T therapy. Encouragingly, two of the CD19-targeted CAR-T therapies, Kymriah and Yescarta, have been approved to treat relapsed/refractory $(r / r)$ pediatric, young adult B cell ALL (B-ALL), and certain adult nonHodgkin lymphomas (NHL) by the US Food and Drug Administration in 2017. Owing to their satisfactory therapeutic effects and clinical safeties [3, 19-21], they have successfully become the first two gene therapies approved in the USA. On present trends, it is doubtless that CAR-T therapy will be generalized to more relapsed and refractory malignancy patients in the near future.

However, the medical safety problems are still in the way of the widespread application of CAR-T therapy. More 
improvements should be made to enhance safety and avoid variable side effects. As previously reported, cytokine release syndrome (CRS) is the major toxicity in CAR-T therapy [1-4, $6,7,9,13,22]$. It is virtually a systemic inflammatory response, caused by the in vivo CAR-T cell activation and proliferation, and the accompanying prominent elevations of multiple serum cytokines [23, 24]. Besides, CAR-T cell-related encephalopathy syndrome (CRES) is also of frequent occurrence in CAR-T therapy [3-7, 9, 16, 22, 25-27]. Passive diffusion of cytokines into the brain, trafficking of T cells into the CNS, and disruption of the blood-brain barrier may contribute to the development of CRES [27]. Most treatment-related death was due to these two adverse events [27]. In addition, the persistence of in vivo CAR-T cells usually contributes to prolonged $\mathrm{B}$ cell aplasia $[22,28,29]$, which can potentially lead to infectious complications [30,31].

In this clinical trial, we also observed that the occurrence rate of coagulopathy during CAR-T therapy was as high as $56.6 \%$, and half of these patients further developed into disseminated intravascular coagulation (DIC). In this article, we present the result of the trial and analyze the pathogenesis of coagulation disorders.

\section{Methods}

\section{Clinical trial design}

In order to assess the safety and evaluate the anti-leukemic effect of CD-19 targeted CAR-T cells in r/r CD19-positive B-ALL patients, we designed a phase $1 / 2$ clinical trial (NCT02965092), which was approved by the medical ethics committee of Union Hospital, Tongji Medical College, Huazhong University of Science and Technology. Patients with $\mathrm{r} / \mathrm{r}$ B-ALL were eligible for enrollment. Informed consent in accordance with the Declaration of Helsinki would be provided to every patient before participation. A leukapheresis to collect peripheral-blood mononuclear cells (PBMCs) for manufacture of CAR-T cells was performed on day -11 . A lymphodepleting chemotherapy regimen comprised fludarabine $\left(30 \mathrm{mg} / \mathrm{m}^{2}\right.$, days $-7,-6$, and -5$)$ and cyclophosphamide $\left(750 \mathrm{mg} / \mathrm{m}^{2}\right.$, days -7 and -6$)$ was administered to reduce baseline tumor burden. The doses of fludarabine and cyclophosphamide would be decreased to 25 and $600 \mathrm{mg} / \mathrm{m}^{2}$ in patients younger than 17 years old. Split infusions of CAR$\mathrm{T}$ cells, with a total amount of 0.89 to $4.01 \times 10^{6} / \mathrm{kg}$ (total T cell amount was 0.5 to $1 \times 10^{7} / \mathrm{kg}$ ), were given to patients intravenously from day 0 to day 2 .

Treatment response of B-ALL was defined on the basis of the National Comprehensive Cancer Network Version 1.2015 (https://www.nccn.org/) and was assessed at 1 month. Adverse events correlated with the therapy were evaluated against the National Institutes of Health Common
Terminology Criteria for Adverse Events Version 4.0. (http:// ctep.cancer.gov/). In particular, the CRS was graded and managed in accordance with the modified CRS grading system [32] and was judged to be severe if it was grade 3 or higher. Additionally, DIC was diagnosed by using the new Chinese DIC Scoring System (CDSS) [33], which was widely used in China and showed good performance on diagnostic and prognostic value in Chinese population $[34,35]$.

\section{CRS diagnosis and management}

Patients who were featured with fever, fatigue, headache, hypotension, and/or neurological toxicities after the infusion of CAR-T cells, with an elevation of various cytokines, could be diagnosed as CRS after the exclusion of active infection. Due to the overlapping symptoms with infection and the preexisting neutropenia in a large amount of patients, CRS should be distinguished from infection. We usually used imaging tests and laboratory tests to identify infection, such as computed tomography, magnetic resonance imaging, bacterial examination, CRP, procalcitonin, etc. As for CRS, we usually emphasized on the detection of cytokines and factors related to macrophage activation syndrome, such as ferritin, triglyceride, and fibrinogen. Empiric antimicrobial prophylaxis and treatment had been applied to possible infections, and specific drugs had been used according to the results of drug susceptibility tests. Grade 1 CRS indicated non-lifethreatening symptoms, including fever, nausea, fatigue, headache, myalgias and/or malaise, and required only symptomatic and support treatment. Grade 2 CRS referred to hypoxia responsive to $<40 \%$ oxygen, or hypotension responsive to fluids or one low dose vasopressor, or grade 2 organ toxicity. Grade 3 CRS meant hypoxia responsive to $\geq 40 \%$ oxygen, or hypotension responsive to multiple or high dose vasopressors, or grade 3 organ toxicity or grade 4 transaminitis. It should be pointed out that high dose vasopressors meant norepinephrine $\geq 20 \mu \mathrm{g} / \mathrm{min}$, or dopamine $\geq 10 \mu \mathrm{g} / \mathrm{kg} / \mathrm{min}$, or phenylephrine $\geq 200 \mu \mathrm{g} / \mathrm{min}$, or epinephrine $\geq 10 \mu \mathrm{g} / \mathrm{min}$, solely, or vasopressin and norepinephrine equivalent of $\geq 10 \mu \mathrm{g} / \mathrm{min}$, or norepinephrine equivalent of $\geq 20 \mu \mathrm{g} / \mathrm{min}$ if on combination vasopressors. Grade 4 CRS indicated life-threatening symptoms requiring ventilator support or grade 4 organ toxicity (excluding transaminitis). Grade 5 CRS referred to death. As for treatment, grade 1 CRS only needed vigilant supportive care, such as antipyretics, analgesics, antibiotics, fluids, and vasopressors. Patients in grade 2 CRS without extensive comorbidities and older age were also suggested supportive treatment, along with close monitoring of organ functions. More severe grade 2 CRS, grade 3 and 4 CRS required supportive treatment and immunosuppressants at the same time. Tocilizumab usually served as the first-line 
immunosuppressant, and corticosteroids should be added when patients showed no response to tocilizumab within $24 \mathrm{~h}$ or developed CRES. Patients with CRS were monitored in terms of both clinical features and laboratory results, such as cytokines and CRP, etc. Serum cytokines, including human interleukin-2 (IL-2), IL-4, IL-6, IL-10, tumor necrosis factor- $\alpha$ (TNF- $\alpha$ ), and interferon- $\gamma$ (IFN- $\gamma$ ), were detected daily by means of flow fluorescence.

\section{CAR-T cell manufacture}

The structure of CAR and the manufacture process of CAR-T cells have been previously described [26]. CD4+ and CD8+ T cells were picked out from PBMCs, which were acquired from patients by leukapheresis, with the use of magnetic beads (Miltenyi Biotec). The two kinds of $\mathrm{T}$ cells were separately cultured in bottles pre-coated with CD3 and CD28, with the existence of IL-2 and IFN- $\gamma$. They were transduced to CAR-T cells (Fig. 1a) with lentivirus vectors encoding anti-CD19 single-chain variable fragment, 4-1BB costimulatory domain, etc. during the following 5 days. Next, the virus vectors would be washed away and tests to ensure effectivity and safety of CAR-T cells would be carried out. When desirable amounts of CD4+ and CD8+ CAR-T cells were attained, a mixture of them would be formed in a 1:1 ratio. Totally, it took approximately 11 days from leukapheresis to infusion (Fig. 1b).

\section{Monitoring in vivo CAR-T cells}

We conducted real-time quantitative polymerase chain reaction (qPCR) and flow cytometry to measure the level of CAR gene and the rates of CAR-T cells in peripheral blood and

bone marrow after CAR-T cell infusion. PCR and flow cytometry were performed on a Biorad CFX-96 machine and a Beckman CytoFLEX S flow cytometer respectively. We used polyclonal goat anti-mouse $\mathrm{F}(\mathrm{ab})_{2}$ antibodies (fluorescein isothiocyanate, FITC) and mouse anti-human CD3 antibodies (allophycocyanin, APC) to identify CAR-T cells by their double positivity for $\mathrm{F}(\mathrm{ab})_{2}$ and $\mathrm{CD} 3 . \mathrm{F}(\mathrm{ab})_{2}$ antibodies and $\mathrm{CD} 3$ antibodies were purchased from Jackson ImmunoResearch (PA, USA) and BD Biosciences (CA, USA), respectively.

\section{TF and PECAM-1 measurements}

We collected patients' plasma by using sodium citrate as anticoagulant and measured tissue factor (TF) and platelet endothelial cell adhesion molecular-1 (PECAM-1) concentrations by ELISA methods (Abcam, UK).

\section{Statistical analysis}

Differences for categorical variables between groups were performed by use of the Chi-square statistic or Fisher's exact test as appropriate. Differences for continuous variables between groups were conducted using Wilcoxon test. Correlation analyses of different continuous variables were made with the application of linear mixed model. Overall survival was measured from the first CAR-T cell infusion to death from any cause, or last visit. Estimates of survival probabilities were calculated by the method of Kaplan and Meier. Differences in survival among subgroups were assessed using the $\log$ rank test. All reported $P$ values were two-sided and were judged to be significant at less than 0.05 . Results were analyzed and figures were produced by GraphPad Prism version 5.0 software and IBM SPSS Statistics 22 software.

Fig. 1 CAR-T cell structure and manufacture. a The chimeric antigen receptor structure comprises anti-CD19 scFv, $\mathrm{CD} 8 \alpha$ hinge, transmembrane domain, and $4-1 \mathrm{BB} / \mathrm{CD} 3 \zeta$, signaling domains. b Autologous T cells were transduced by lentivirus to produce CAR-T cells. Abbr: scFv, single chain variable fragment a

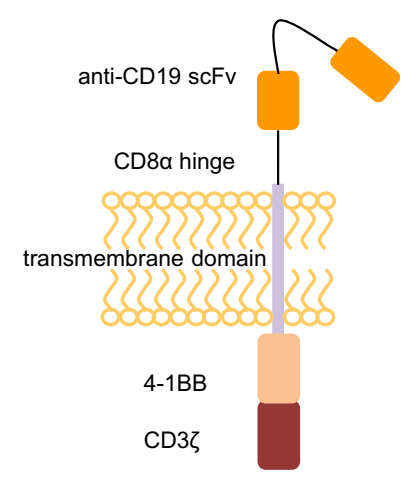

b

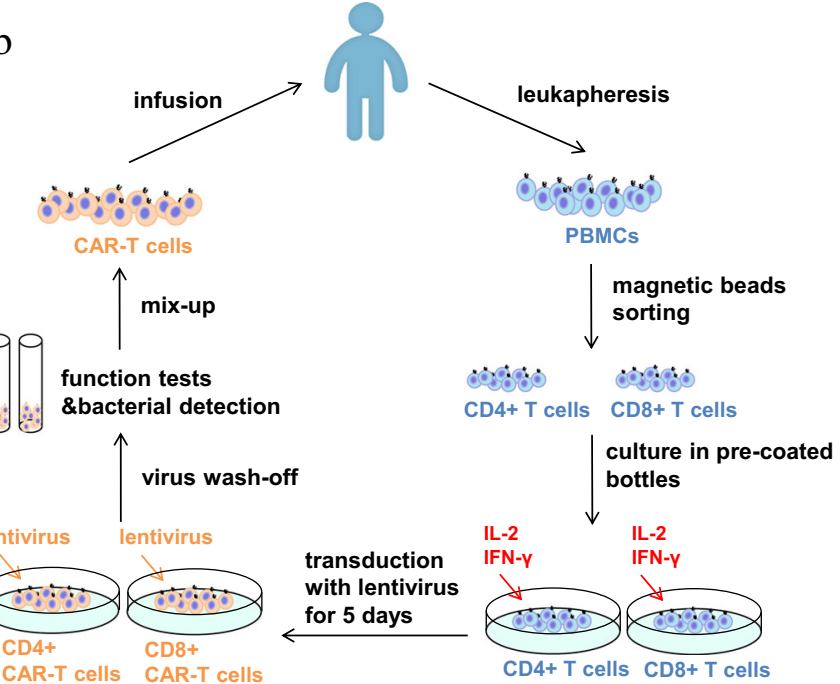




\section{Results}

\section{Outcomes}

Fifty-three CD19-positive r/r B-ALL patients, ranging from 10 to 61 years old, had received CAR-T therapy at Union Hospital, Tongji Medical College, Huazhong University of Science and Technology. More than half of the enrollers had high disease burdens ( $\geq 5 \%$ bone marrow blasts) before CAR$\mathrm{T}$ cell infusion, and six patients were with Philadelphia chromosome-positive diseases (Table 1).

Flow cytometry results with bone marrows were used to assess clinical responses of patients. Forty-seven of the 53 patients successfully reached complete remissions (CR) at 1month time point after CAR-T therapy, including 43 minimal residual disease-negative (MRD-) $\mathrm{CR}$ and 4 minimal residual disease-positive (MRD+) CR. Nevertheless, six patients showed no response (NR) to CAR-T therapy.

With a median follow-up time of 6.6 months (range, 0.7 to 31.4 ), the median overall survival (OS) was 16.1 months. The 6-month and 12-month OS rates were 69.727\% and 64.028\%, respectively. Twenty-one patients suffered relapses from 1.1 to 15.6 months (median 3.4) after CAR-T therapy. Notably, two patients received CAR-T cell infusions for 3 more times from 1 to 6 months to strengthen therapeutic effects, but they still developed CD19-positive relapses at 10 months and 16 months, respectively. Thereafter, they were transferred to the second anti-CD19 CAR-T therapy. However, they did not respond to CAR-T therapy again. Moreover, 20 patients died

Table 1 Characteristics of 53 patients

\begin{tabular}{ll}
\hline Characteristics & Values and percentages \\
\hline Age (years old) & \\
$0-17$ & $4(7.5 \%)$ \\
$18-30$ & $29(54.7 \%)$ \\
$31-65$ & $20(37.7 \%)$ \\
Philadelphia chromosome-positive & \\
Yes & $6(11.3 \%)$ \\
No & $47(88.7 \%)$ \\
Previous allo-HSCT & \\
Yes & $2(3.8 \%)$ \\
No & $51(96.2 \%)$ \\
Pre-infusion disease burden & \\
$\geq 5 \%$ & $33(62.3 \%)$ \\
$\geq 0.01 \%$ and $<5 \%$ & $14(26.4 \%)$ \\
$<0.01 \%$ & $6(11.3 \%)$
\end{tabular}

${ }^{\mathrm{a}}$ Percentages may not equal $100 \%$ due to rounding

${ }^{\mathrm{b}}$ Pre-infusion disease burden was assessed by means of flow cytometry immediately before CAR-T cell infusion

allo-HSCT allogeneic hematological stem cell transplantation by reason of disease relapse or progression or serious treatment-related adverse events.

\section{Persistence of CD19 CAR-T cells}

The persistence of CAR-T cells was continuously monitored by qPCR and flow cytometry. Nonetheless, limited by patients' choices to subsequent therapies, such as allogeneic hematological stem cell transplantation, the analysis of CAR-T cell persistence could not proceed for the whole follow-up time. The statistics indicated that most patients experienced the climax of in vivo CAR-T cells within two weeks, and the longest persistence time of CAR-T cells in both peripheral blood and bone marrow was 18 months.

\section{Cytokine release syndrome}

In our clinical trial, all patients experienced CRS, 34 of them were mild (grade $\leq 2$ ), and the other 19 were severe (grade $\geq 3$ ) (Table 2). Similar to previous report [1-5], we observed high temperatures, chills and rigors, hypotension, hypoxia, respiratory or cardiac or renal insufficiency, and neurological toxicities in CRS patients. In addition to these, we found that coagulation disorders also occurred frequently in CRS patients during treatment courses. The highest and most common cytokine elevations were seen in IL- 6 , IL-10, and TNF- $\alpha$. Our trial data presented a positive correlation between CRS severity and the baseline tumor burden before CAR-T cell infusion. Normally, severe CRS was significantly related to a higher tumor burden ( $\geq 5 \%$ bone marrow blasts) $(P=0.003)$. Meanwhile, we found that CRS severity had no influence on 1-month remission rate and disease recurrence rate $(P>0.05)$.

According to the grading scale proposed by Lee et al. [32], patients with grade $3 / 4$ CRS and patients with grade 2 CRS with extensive comorbidities or older age were applied with tocilizumab and/or corticosteroids. Tocilizumab was used at the dose of $4 \mathrm{mg} / \mathrm{kg}$ for adults and $8 \mathrm{mg} / \mathrm{kg}$ for children. The second dose of tocilizumab and/or steroids would be given if there was no improvement within $24 \mathrm{~h}$. Notably, steroids were considered as the first-line treatment in patients developed CRES, as tocilizumab cannot cross the blood-brain barrier. Generally, methylprednisolone was used at the initial dose of $2 \mathrm{mg} / \mathrm{kg} /$ day and was tapered over several days. Dexamethasone was applied at the dose of $0.5 \mathrm{mg} / \mathrm{kg}$ in patients with severe CRES, and the maximum single dose was $10 \mathrm{mg}$. During the study, 21 patients received tocilizumab and 13 patients received steroids. Except for one patient who died on day 21, other patients survived from CRS.

\section{Thirty patients developed coagulation disorders}

Considering the abnormal laboratory indicators and the clinical manifestations, we judged that 30 of the 53 patients experienced 
Table 2 CRS grading and management in patients

\begin{tabular}{cll}
\hline CRS grade & $\begin{array}{l}\text { Number of } \\
\text { patients }\end{array}$ & Treatment $^{\mathrm{a}}$ \\
\hline 1 & 21 & $\begin{array}{l}\text { - Supportive care: antipyretics, analgesics, antibiotics, } \\
\text { fluids and vasopressors } \\
\text { - Supportive care + close monitoring of organ functions } \\
\text { - Tocilizumab and/or corticosteroids for extensive } \\
\text { comorbidities and older age }\end{array}$ \\
3 & 13 & $\begin{array}{l}\text { S Supportive care + tocilizumab and/or corticosteroids } \\
\text { - Supportive care + tocilizumab and/or corticosteroids }\end{array}$ \\
\hline
\end{tabular}

${ }^{\text {a }}$ One of the grade 2 CRS patients, 11 of the grade 3 CRS patients, and 3 of the grade 4 CRS patients were diagnosed with DIC, they also received anticoagulant treatment and replacement treatment

coagulation disorders during CAR-T therapy. Patients always started to become coagulopathy around day 8 to day 10 , closely following IL-6 rise. We observed the phenomenon that with the control of CRS and the declines of multiple cytokines, coagulation problems usually resolved spontaneously.

Laboratory examination results always changed prior to the occurrence of clinical manifestations. Twenty-seven patients experienced platelet count reductions, and 30 patients were out of normal ranges of coagulation indicators. Among the coagulopathy patients, the nadir value of platelet counts and fibrinogen ranged from 5 to $47 \times 10^{9} / \mathrm{L}$ (median, 17) and 0.59
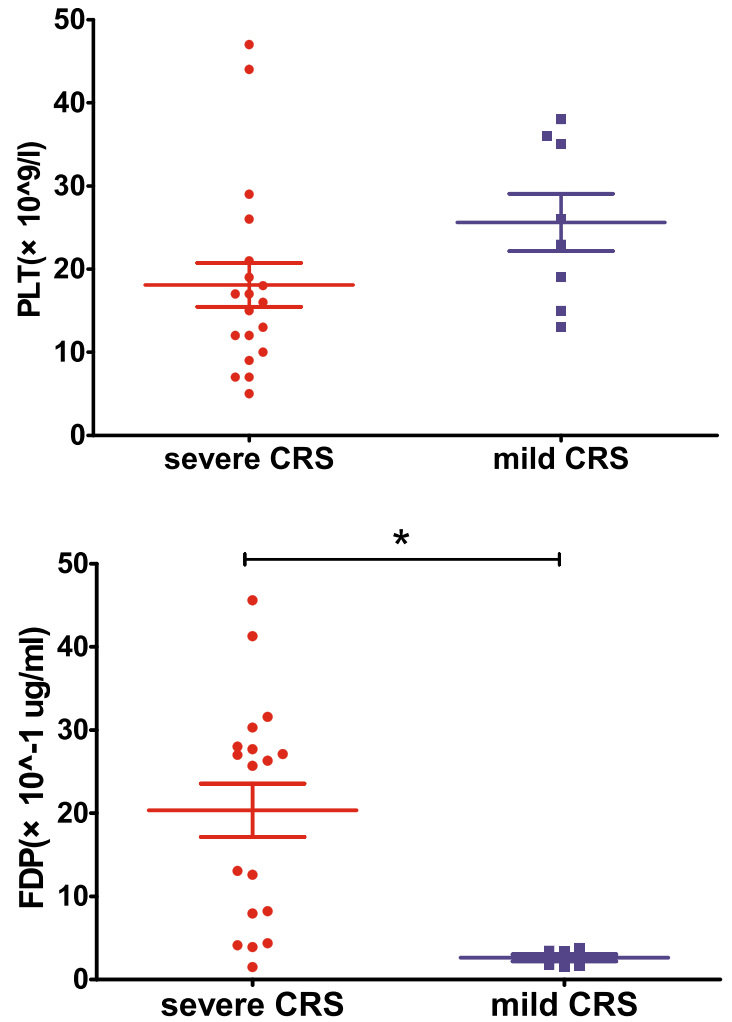

Fig. 2 Abnormal laboratory coagulation indicators. Data represented the mean \pm SEM. $P$ values were determined using the Wilcoxon test. Because no mild CRS patient became abnormal in PT, FIB, and TT levels, the three indicators were not analyzed in this part. Abbr: PLT, platelet count; to $0.82 \mathrm{~g} / \mathrm{L}$ (median, 0.66), respectively; the peak value of $\mathrm{D}$ dimer and fibrin degradation products (FDP) ranged from 5.3 to $44 \mathrm{mg} / \mathrm{L}$ (median, 21) and 14.7 to $456 \mu \mathrm{g} / \mathrm{mL}$ (median, 104.1), respectively; the peak value of prothrombin time (PT) and activated partial thromboplastin time (APTT) ranged from 20 to $26.7 \mathrm{~s}$ (median, 22.3) and 54.2 to $90.2 \mathrm{~s}$ (median, $60.9)$, respectively. The most significant changes of laboratory results were decreased platelet counts, increased FDP, and prolongation of APTT. Further analysis revealed that there were significant differences of D-Dimer and FDP levels between severe and mild CRS patients $(P<0.05)$ (Fig. 2).
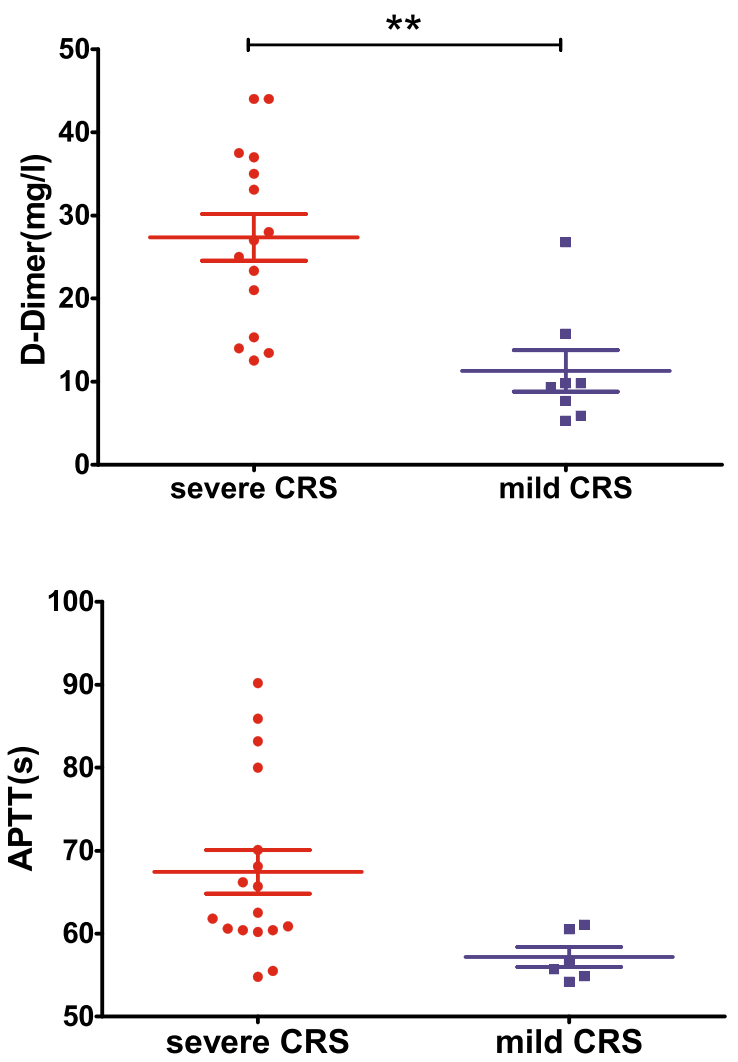

FDP, fibrin degradation products; PT, prothrombin time; APTT, activated partial thromboplastin time; FIB, fibrinogen; TT, thrombin time; CRS, cytokine release syndrome; SEM, standard error of mean; $* 0.01<$ $P<0.05 ; * * P<0.01$ 
Except for laboratory results, hemorrhage was the most evident manifestation that indicated coagulopathy. Petechiae and ecchymosis could be found on trunk or four limbs; unusual bleeding sometimes happened in nasal and oral mucosa, and sclera; no intracranial hemorrhage happened in our trial.

Moreover, we observed that all 19 severe CRS patients experienced coagulation disorders, while only 11 of 34 mild CRS patients did. These data showed that severe CRS patients were more likely to develop coagulopathy $(P<0.0001)$. Therefore, we defined the coagulation problems during CAR-T therapy as CRS-related coagulopathy.

\section{Fifteen patients diagnosed as DIC according to Chinese DIC Scoring System}

Among the 30 patients who had coagulation problems, 15 were further diagnosed as DIC in line with CDSS [33] (Table 3). The symptoms of DIC varied from mild and selflimiting, with ecchymosis and jaundice, to severe and life- threatening, with hypotension, dyspnea, renal dysfunction, neurological disorders, and even shock (Table 4). While $73.7 \%$ severe CRS patients developed DIC, only $2.9 \%$ mild CRS patients did. Therefore, we drew a conclusion that compared to mild CRS patients, DIC were more commonly seen in severe CRS patients $(P<0.0001)$.

During the first month of CAR-T therapy, we assessed coagulation by standard methods every day. Thrombelastometry was also used, but the results were not used to confirm DIC. Once a patient began to develop coagulopathy, we graded him by CDSS daily to evaluate his coagulation function and pathogenetic condition and adjusted the treatment plan accordingly. While alleviating the underlying condition and controlling CRS, we selectively applied anticoagulant treatment, such as heparin, and replacement treatment, including supplements of fresh-frozen plasma, cryoprecipitate, fibrinogen and platelet concentrate, and antifibrinolytic treatment to these DIC patients under different circumstances. To be specific, patients at hypercoagulable stage (early stage), featured with extensive

Table 3 DIC patients' scores according to CDSS

\begin{tabular}{|c|c|c|c|c|c|c|c|c|c|c|c|c|c|c|c|c|}
\hline \multirow[t]{2}{*}{ Items } & \multirow[t]{2}{*}{ Score } & \multicolumn{15}{|c|}{ Number } \\
\hline & & 1 & 2 & 3 & 4 & 5 & 6 & 7 & 8 & 9 & 10 & 11 & 12 & 13 & 14 & 15 \\
\hline 1.Uderlying disease $\mathrm{e}^{\mathrm{a}}$ & 2 & 2 & 2 & 2 & 2 & 2 & 2 & 2 & 2 & 2 & 2 & 2 & 2 & 2 & 2 & 2 \\
\hline $\begin{array}{l}\text { 2.Clinical manifestations(meet anyone) } \\
\text { (1)shock or microcirculatory disorder } \\
\text { independent of original disease } \\
\text { (2)unexplained organ failure }\end{array}$ & 1 & 1 & 0 & 0 & 0 & 0 & 0 & 1 & 0 & 0 & 1 & 1 & 0 & 0 & 0 & 1 \\
\hline \multicolumn{17}{|l|}{$\begin{array}{l}\text { 3.Laboratory examinations } \\
\text { (1)Platelet count }\left(\times 10^{9} / \mathrm{L}\right)\end{array}$} \\
\hline$\geq 50$ & 0 & & & & & & & & & & & & & & & \\
\hline$<50$ & 1 & 1 & 1 & 1 & 1 & 1 & 1 & 1 & 1 & 1 & 1 & 1 & 1 & 1 & 1 & 1 \\
\hline $\begin{array}{l}\geq 50 \% \text { decrease within } 24 \mathrm{~h} \\
\text { (2)D-Dimer }(\mathrm{mg} / \mathrm{L})\end{array}$ & \multicolumn{15}{|c|}{ (2)D-Dimer(mg/L) } & \\
\hline$<5$ & 0 & & & & & & & & & & & & & & & \\
\hline $5-9$ & 2 & & & & & & & & & & & & & & & \\
\hline$\geq 9$ & 3 & 3 & 3 & 3 & 3 & 3 & 3 & 3 & 3 & 3 & 3 & 3 & 3 & 3 & 3 & 3 \\
\hline \multicolumn{17}{|l|}{ (3)Prolongation of PT and APTT } \\
\hline $\begin{array}{l}\text { Prolongation of } \mathrm{PT}<3 \mathrm{~s} \text { and } \\
\text { prolongation of } \mathrm{APTT}<10 \mathrm{~s}\end{array}$ & 0 & & & 0 & & & & & & & 0 & & & & & \\
\hline $\begin{array}{l}\text { Prolongation of } \mathrm{PT} \geq 3 \mathrm{~s} \text { or } \\
\text { prolongation of } \mathrm{APTT} \geq 10 \mathrm{~s}\end{array}$ & 1 & 1 & 1 & & 1 & & 1 & 1 & 1 & 1 & & 1 & 1 & 1 & 1 & \\
\hline Prolongation of $\mathrm{PT} \geq 6 \mathrm{~s}$ & 2 & & & & & 2 & & & & & & & & & & 2 \\
\hline \multicolumn{17}{|l|}{ 4.Fibrinogen $(\mathrm{g} / \mathrm{L})$} \\
\hline$\geq 1.0$ & 0 & 0 & 0 & & & 0 & 0 & & & 0 & 0 & & 0 & 0 & 0 & \\
\hline$<1.0$ & 1 & & & 1 & 1 & & & 1 & 1 & & & 1 & & & & 1 \\
\hline Total scores ${ }^{\mathrm{b}}$ & & 8 & 7 & 7 & 8 & 8 & 7 & 9 & 8 & 7 & 7 & 9 & 7 & 7 & 7 & 10 \\
\hline
\end{tabular}

${ }^{a}$ Underlying diseases included infection, solid tumors, autoimmune diseases, trauma/post-surgery/poisoning, obstetric complications, vascular anomalies, shock/hypoxic-ischemic, severe liver disease (unreached Child-Pugh $\mathrm{C}$ grade), hematologic malignancies, and others

${ }^{\mathrm{b}}$ Diagnosis: 6 points or more

$P T$ prothrombin time, APTT activated partial thromboplastin time 
Table 4 Symptoms in the 15 DIC patients

\begin{tabular}{lc}
\hline Symptoms of DIC & No. of patients \\
\hline Ecchymosis & 15 \\
Jaundice & 7 \\
Hypotension & 10 \\
Dyspnea & 11 \\
Renal dysfunction & 8 \\
Neurological disorders & 5 \\
Shock & 2 \\
\hline
\end{tabular}

microthrombosis and normal/shortened APTT and PT, were treated with anticoagulant treatment; patients at consumptive hypocoagulable stage (middle stage), featured with severe or multiple bleeding, prolonged APTT and PT, progressively decreased platelet count and fibrinogen level and slightly increased D-Dimer and FDP level, were treated with replacement treatment on the basis of anticoagulant treatment; patients at secondary hyperfibrinolysis stage (late stage), featured with hemorrhage, prolonged APTT and PT, decreased platelet count and fibrinogen level and significant increased D-Dimer and FDP level, were treated with antifibrinolytic treatment when the underlying disease and inducement were removed or controlled. In addition to the above treatment, 15 DIC patients received tocilizumab and 11 received steroids. Interestingly, the laboratory results and bleeding symptoms would improve after the application of tocilizumab and/or steroids. Four patients were rescued from DIC 4 days after the application of tocilizumab/steroids, 8 patients were rescued 7 days after the application, and 2 patients were rescued 14 days later. We speculated that the immunosuppressant could suppress the generation of inflammatory cytokines, thus protecting vessels from further damage and relieving the symptoms of coagulopathy.

Based on proper and prompt therapy, 14 patients who suffered from DIC fortunately got off the tough situations. Successful treatment experience had been published before [26]. However, one 28-year-old woman developed intermittent fever since day 4, accompanied by vomiting and diarrhea. The condition deteriorated on day 14, and she required admission to the intensive care unit (ICU). She was judged as grade $4 \mathrm{CRS}$, mainly manifested as uncontrollable DIC and NT. Despite the application of tocilizumab, corticosteroid, vasopressor, blood products, and anticoagulant, the patient developed multiple organ dysfunction syndromes (MODS) and died of alimentary tract hemorrhage on day 21. In spite of the fatal adverse event, the follow-up study showed that there was no difference in patients' survival rates between DIC patients and non-DIC patients $(P>0.05)$ (Fig. 3). However, we speculated a worse prognosis in DIC patients without reasonable treatment.

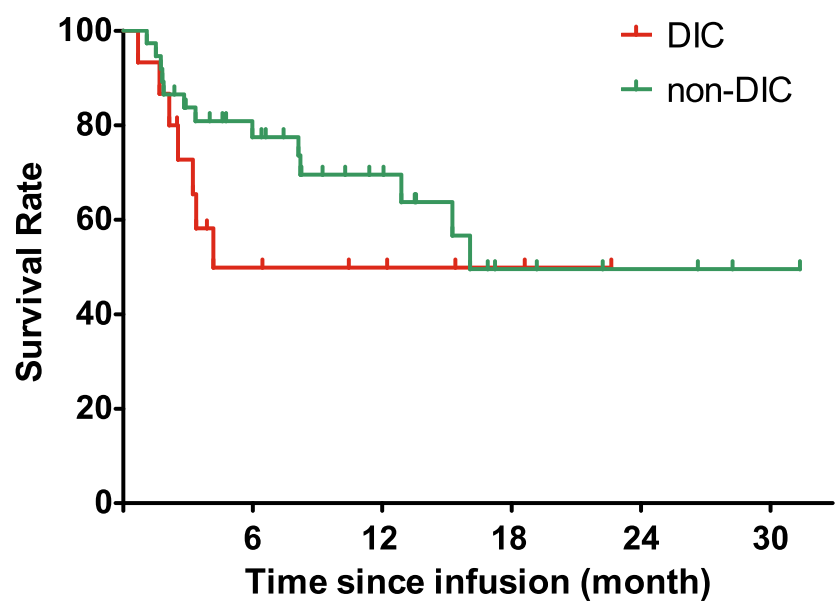

Fig. 3 Survival analysis of DIC and non-DIC patients. The survival probabilities were estimated with the application of the Kaplan-Meier method, and $P$ value was calculated by the log-rank test. Abbr: DIC, disseminated intravascular coagulation

\section{PECAM-1 and TF are critical parameters in the process of CRS-related coagulopathy}

In view of the fact that most DIC occurred in severe CRS patients, we further analyzed the relationship between coagulation laboratory indicators and cytokines and found that the variation trends of them were consistent. Realizing this, we continuously collected the plasma of the next 15 patients for 1 month and measured the concentrations of TF and PECAM1. These two vascular endothelial molecules play important roles in the process of coagulation.

Among the 15 patients, 9 experienced mild CRS, and the other 6 experienced severe CRS. We found that severe CRS patients had higher plasma TF and PECAM-1 concentrations compared to mild CRS patients $(P<0.05)$ (Fig. 4a, b) Four patients developed DIC and severe CRS at the same time, the statistics revealed positive correlations between the 2 molecules and IL-6 $(P<0.05)$, which suggested that vascular endothelium played important role in CRS-related coagulopathy. (Fig. 4c f).

\section{Discussion}

Our research group conducted a CD19-targeted CAR-T clinical trial for $\mathrm{r} / \mathrm{r}$ B-ALL patients, 47 of the 53 patients reached remissions at 1 -month time point. There were $35.8 \%$ and $15.1 \%$ patients developing grade 3-4 CRS and grade 2-3 CRES, respectively. In addition to CRS and CRES, coagulopathy also occurred frequently. Interestingly, coagulopathy and DIC were more often observed in severe CRS patients, so we defined it as CRS-related coagulopathy. The statistics demonstrate that coagulation disorders are general side effects during CAR-T therapy. In order to comprehensively improve the 

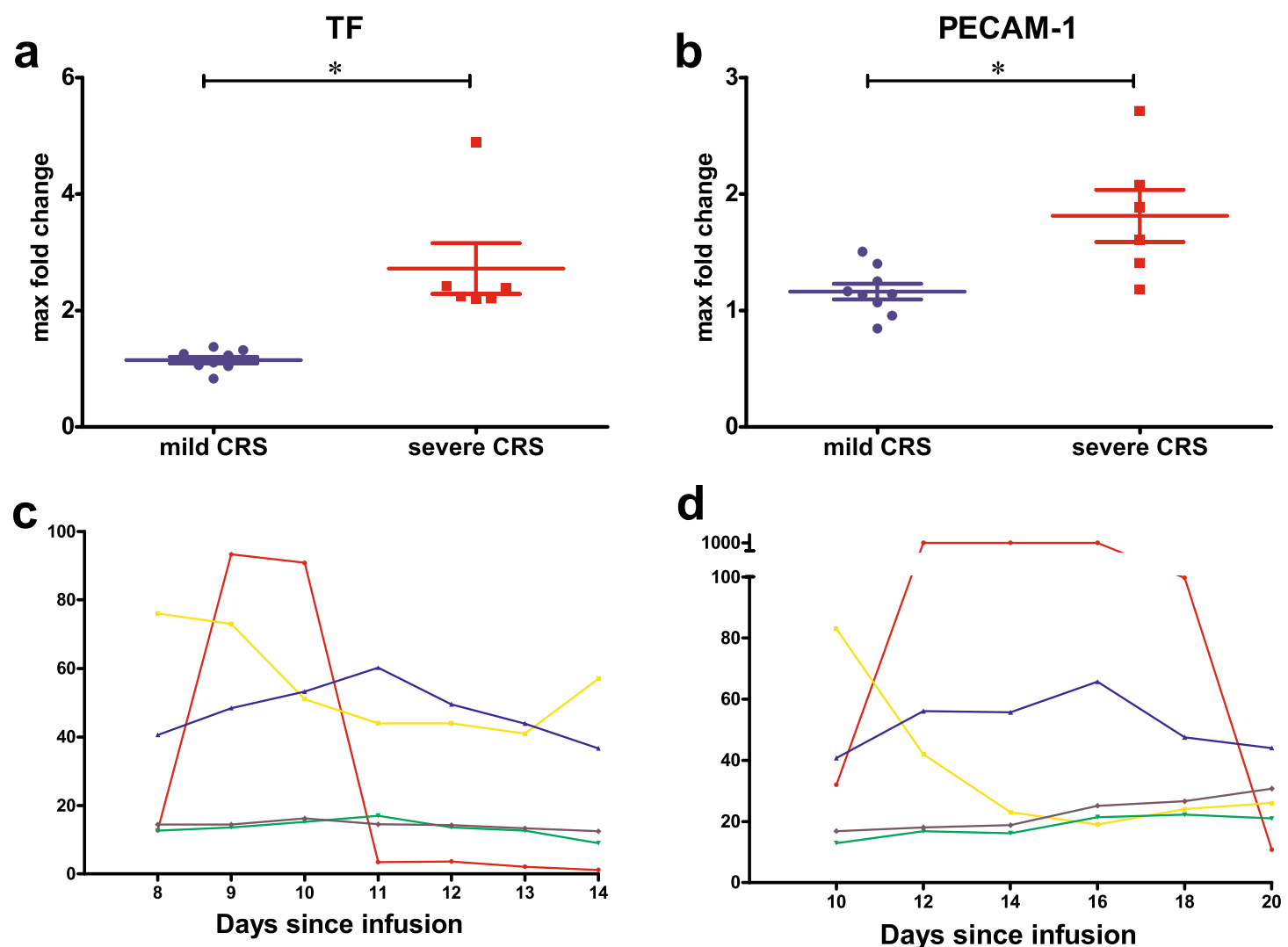

d
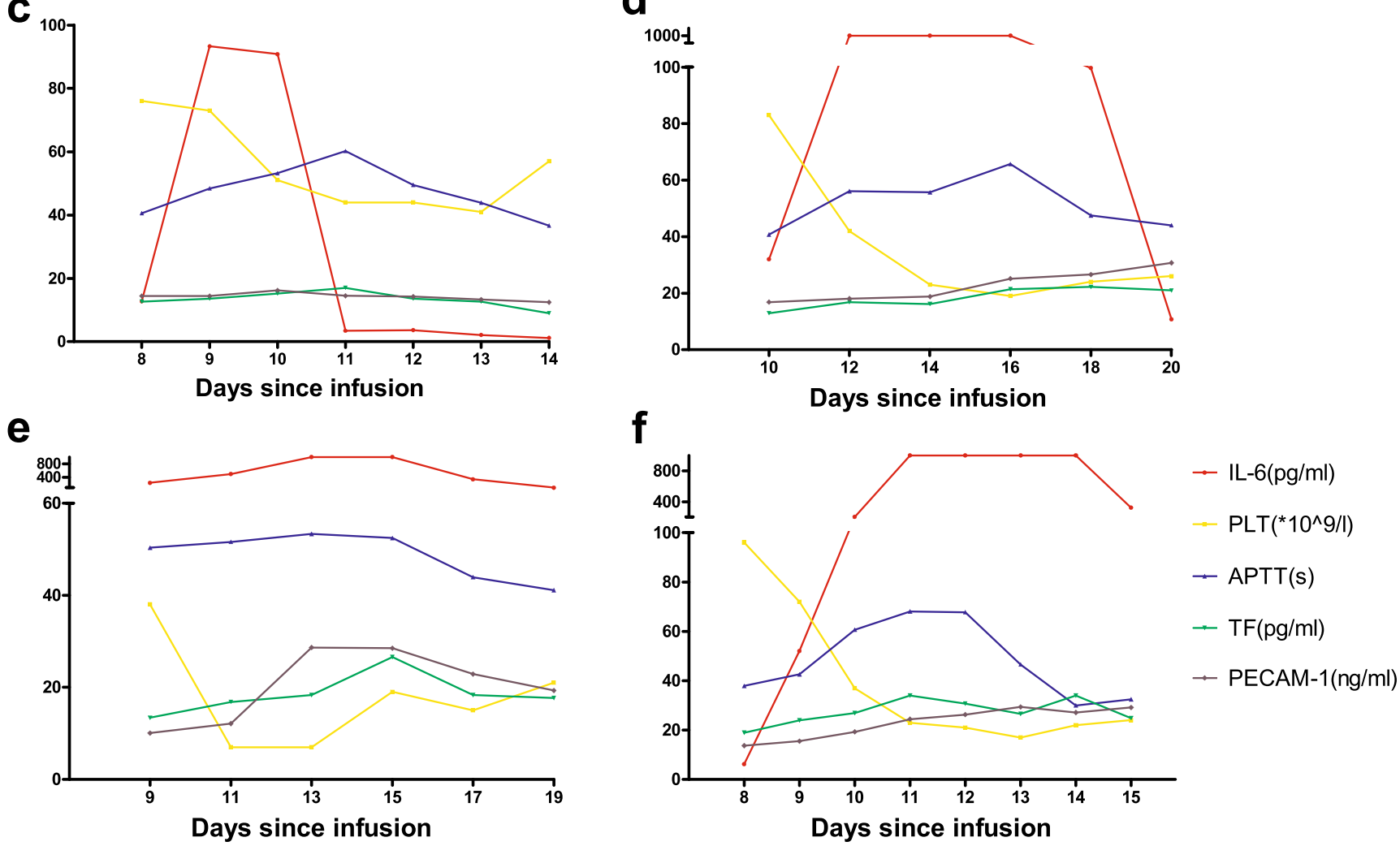

Fig. 4 Plasma TF and PECAM-1 levels in patients. a, b The max fold changes of post-infusion plasma TF and PECAM-1 concentrations compared to the baseline concentrations at day 0 . Data represented the mean \pm SEM. $P$ values were determined with the use of the Wilcoxon test. c $\sim$ f IL6 , PLT, APTT, TF, and PECAM-1 levels in the 4 patients who developed

DIC and severe CRS at the same time. Abbr: IL, interleukin; PLT, platelet count; APTT, activated partial thromboplastin time; TF, tissue factor; PECAM-1, platelet endothelial cell adhesion molecular-1; SEM, standard error of mean; $* 0.01<P<0.05$

safety of CAR-T therapy, investigators are supposed to further study the mechanisms of CRS-related coagulopathy and seek out rational solutions.

Inflammation and endothelium play extremely important roles in the development and progression of DIC. During inflammation, large amount of released inflammatory factors would damage the vascular endothelium and destroy the endothelial barrier integrity, resulting in decreased cell surface PECAM-1 and increased plasma soluble PECAM-1 [36].
PECAM-1 is a molecular which expresses highly at endothelial cell intercellular junctions and maintains vascular endothelial integrity [37]. On the other hand, endothelium damage causes overexpression of $\mathrm{TF}$, which activates the extrinsic route of blood coagulation. In all, excessive inflammatory reaction and endothelial barrier destruction in DIC would promote each other and create a vicious cycle, which eventually result in systemic microvascular thrombosis, massive consumption of coagulation factors, and secondary 
hyperfibrinolysis, manifesting as microcirculation disturbance and bleeding. Based on the close connection of pathophysiologic mechanisms between inflammation and coagulation, and the awareness that CRS is a kind of inflammation reaction, we make a reasonable assumption that the cytokines released from inflammatory cells during CRS may lead to dysfunction of endothelial cells and destroy the integrity of endothelial barrier, thus eventually causing CRS-related coagulopathy. In line with the hypothesis, our data showed synchronous elevations of plasma TF and PECAM-1 concentrations in severe CRS and DIC patients, which partly confirmed endothelium damage resulting from massive cytokines. The results are similar to those in the inflammation-coagulation model induced by silica nanoparticles in zebrafish embryos [38]. Likewise, endothelial activation was observed in other groups and was proved to be critical factors of the subsequent coagulopathy and CRES $[39,40]$. Nonetheless, further research in animal models is expected to provide deeper understanding of the specific mechanism of CRS-related coagulopathy.

There are a variety of harms of coagulopathy, varying from hemorrhage to microembolization, which may cause changes of biochemical indices, insufficiencies of liver and kidney, abnormalities of central nervous system, and even MODS. Therefore, we speculate that CRS-related coagulation disorders may be one of the main reasons for multiple organ dysfunctions in CAR-T therapy. Under severe coagulopathy circumstances, such as DIC, patients may easily die without early diagnosis and proper treatment. From experience of dealing with CRS-related coagulopathy, we recommend CDSS [33] as an applicable tool for better diagnosis and management of DIC. As long as any coagulopathy manifestation arises, DIC grading should be carried out every day so as to confirm the start and end time point of DIC and to dynamically monitor the severity of DIC. According to the DIC scores and actual clinical situations, physicians can correctly choose appropriate anticoagulant and replacement treatment for patients. Importantly, we should always keep in mind that the treatment of primary disease is the cornerstone of the treatment of DIC. In consideration of the pathogenesis of CRSrelated coagulopathy, effective control of CRS would help to block the progress of DIC. Except for traditional treatment, novel agents against DIC are expected. TF and PECAM-1 were indispensable factors in the pathogenesis of CRSrelated coagulopathy. Animal studies have demonstrated that antibodies to TF could reduce the mortality of sepsisassociated DIC [41, 42] and that endothelial PECAM-1 could protect PECAM-1-deficient mice from endotoxic shock [43]. Hence, TF and PECAM-1 may possibly be new therapeutic targets to improve microcirculation and control CRS-related coagulopathy, thus enhancing the safety of CAR-T therapy.

There are two advantages of closely monitoring coagulation. On the one hand, it may help to make the diagnosis of severe CRS. The current main grading scales, including CTCAE v4.0, grading scale proposed by Lee et al., and Penn grading scale, were all based on clinical features [44]. However, it is undeniable that the levels of cytokines and CRP were closely related to the severity of CRS. A large study revealed strong correlation of peak value of parameters such as CRP and IL-6 with CRS [24], and some researchers used the combination of clinical manifestations and serum cytokine and CRP levels as criteria for severe CRS [4]. Notably, the baseline cytokine levels may be high in some patients, so it would be better to take fold increases, net increases, or rate of change in cytokine levels as criteria. Compared to the clinical features in the current grading scales, which are difficult to standardize and require detailed review to document, the cytokine and CRP levels may serve as simpler and more objective and accurate indicators to identify severe CRS. Similarly, levels of coagulation factors, including D-Dimer and FDP, had statistically significant differences between mild and severe CRS; and there were positive correlations between APTT, D-Dimer, FDP, PT levels, and IL-6 levels $(P<0.05)$. Moreover, some hospitals do not have access to rapidturnaround measurements of cytokines, so coagulation factors may sometimes act as timely alternatives of cytokines. It is also found that, in inflammatory condition, cytokines will promote the formation of immunothrombosis, which may progress into DIC if the inflammation and coagulation reaction go out of control [45]. So it stands to reason that coagulation factors are closely related to inflammation and can serve as part of the criteria for severe CRS. On the other hand, closely monitoring will help us recognize coagulopathy and start intervention at early phase. Owing to the close relationship of pathophysiology between coagulopathy and CRS, the occurrence of DIC was always concomitant with severe CRS, and the clinical manifestations of DIC such as hemorrhage were always accompanied by CRS symptoms, including fever, hypotension, or others. In the study, a 28-year-old woman developed DIC and severe CRS at the same time, and finally died of alimentary tract hemorrhage on day 21. Other DIC patients survived under timely and intensive treatment [26], but they spent more efforts on the treatment of severe complications and required longer duration of hospital stays. Although Kaplan-Meier analysis showed no difference in patients' survival rates between DIC patients and non-DIC patients, we speculated worse clinical outcomes in DIC patients without appropriate treatment. Therefore, recognition of coagulopathy and treatment at early phase would contribute to improved quality of life of patients and rational use of medical resources. In all, monitoring coagulation could help diagnose and manage CRS, thus reducing the occurrence of poor outcomes of patients.

To conclude, the study verified that anti-CD19 CAR-T therapy had great therapeutic effect on $\mathrm{r} / \mathrm{r}$ B-ALL patients. Furthermore, coagulation disorders are common side effects 
and are closely connected to CRS; proper intervention to CRS-related coagulopathy in the early stage helps a lot to guarantee the security and to reduce the mortality in CAR-T therapy.

Authors' contributions HJ and JDong manufactured CAR-T cells. TG, YW, JDeng, LA contributed to clinical data collection and analysis. HJ measured TF and PECAM-1 levels. HM and YH designed the study. HJ, TG, LL, and HM performed the clinical trial. HJ and HM wrote and revised the manuscript. All authors read and approved the final manuscript.

Funding information This work was supported by grants from the National Natural Science Foundation of China (No. 81770132 \& 81873434) and Major Technological Innovation Special Project of Hubei Province of China (No. 2018ACA141).

\section{Compliance with ethical standards}

Ethics approval and consent to participate The medical ethics committee of Union Hospital, Tongji Medical College, Huazhong University of Science and Technology has reviewed the trial protocol and allowed the trial to proceed. All patients provided written informed consent.

Conflict of interest JDong is an employee of Wuhan Sian Medical Technology Co., Ltd. The other authors declare no competing interests.

Abbreviations CAR, chimeric antigen receptor; CRS, cytokine release syndrome; DIC, disseminated intravascular coagulation; CDSS, Chinese DIC Scoring System; ALL, acute lymphoblastic leukemia; NHL, nonHodgkin lymphoma; HSCT, hematological stem cell transplantation; qPCR, quantitative polymerase chain reaction; FITC, fluorescein isothiocyanate; APC, allophycocyanin; IL, interleukin; TNF- $\alpha$, tumor necrosis factor- $\alpha$; IFN- $\gamma$, interferon- $\gamma$; CR, complete remissions; MRD, minimal residual disease; $\mathrm{CRi}$, complete remissions with incomplete blood count recoveries; NR, no response; allo-HSCT, allogeneic hematological stem cell transplantation; CI, confidence interval; PLT, platelet count; FDP, fibrin degradation products; PT, prothrombin time; APTT, activated partial thromboplastin time; FIB, fibrinogen; TT, thrombin time; $\mathrm{Ph}$, Philadelphia chromosome; ICU, intensive care unit; MODS, multiple organs dysfunction syndromes; SEM, standard error of mean

\section{References}

1. Brentjens RJ, Davila ML, Riviere I, Park J, Wang X, Cowell LG, Bartido S, Stefanski J, Taylor C, Olszewska M, Borquez-Ojeda O, Qu J, Wasielewska T, He Q, Bernal Y, Rijo IV, Hedvat C, Kobos R, Curran K, Steinherz P, Jurcic J, Rosenblat T, Maslak P, Frattini M, Sadelain M (2013) CD19-targeted T cells rapidly induce molecular remissions in adults with chemotherapy-refractory acute lymphoblastic leukemia. Sci Transl Med 5(177):177ra38. https://doi.org/ 10.1126/scitranslmed.3005930

2. Grupp SA, Kalos M, Barrett D, Aplenc R, Porter DL, Rheingold SR, Teachey DT, Chew A, Hauck B, Wright JF, Milone MC, Levine BL, June CH (2013) Chimeric antigen receptor-modified $\mathrm{T}$ cells for acute lymphoid leukemia. N Engl J Med 368(16): 1509-1518. https://doi.org/10.1056/NEJMoa1215134

3. Maude SL, Frey N, Shaw PA, Aplenc R, Barrett DM, Bunin NJ, Chew A, Gonzalez VE, Zheng ZH, Lacey SF, Mahnke YD, Melenhorst JJ, Rheingold SR, Shen A, Teachey DT, Levine BL,
June CH, Porter DL, Grupp SA (2014) Chimeric antigen receptor T cells for sustained remissions in leukemia. N Engl J Med 371(16): 1507-1517. https://doi.org/10.1056/NEJMoa1407222

4. Davila ML, Riviere I, Wang X, Bartido S, Park J, Curran K, Chung SS, Stefanski J, Borquez-Ojeda O, Olszewska M, Qu J, Wasielewska T, He Q, Fink M, Shinglot H, Youssif M, Satter M, Wang Y, Hosey J, Quintanilla H, Halton E, Bernal Y, Bouhassira DCG, Arcila ME, Gonen M, Roboz GJ, Maslak P, Douer D, Frattini MG, Giralt S, Sadelain M, Brentjens R (2014) Efficacy and toxicity management of 19-28z CAR T cell therapy in B cell acute lymphoblastic leukemia. Sci Transl Med 6(224):224ra25. https://doi.org/ 10.1126/scitranslmed.3008226

5. Lee DW, Kochenderfer JN, Stetler-Stevenson M, Cui YK, Delbrook C, Feldman SA, Fry TJ, Orentas R, Sabatino M, Shah NN, Steinberg SM, Stroncek D, Tschemia N, Yuan C, Zhang H, Zhang L, Rosenberg SA, Wayne AS, Mackall CL (2015) T cells expressing CD19 chimeric antigen receptors for acute lymphoblastic leukaemia in children and young adults: a phase 1 doseescalation trial. Lancet 385(9967):517-528. https://doi.org/10. 1016/s0140-6736(14)61403-3

6. Turtle CJ, Hanafi LA, Berger C, Gooley TA, Cherian S, Hudecek M, Sommermeyer D, Melville K, Pender B, Budiarto TM, Robinson E, Steevens NN, Chaney C, Soma L, Chen XY, Yeung C, Wood B, Li D, Cao JH, Heimfeld S, Jensen MC, Riddell SR, Maloney DG (2016) CD19 CAR-T cells of defined CD4(+): CD8(+ ) composition in adult B cell ALL patients. J Clin Invest 126(6): 2123-2138. https://doi.org/10.1172/jci85309

7. Gardner RA, Finney O, Annesley C, Brakke H, Summers C, Leger K, Bleakley M, Brown C, Mgebroff S, Kelly-Spratt KS, Hoglund V, Lindgren C, Oron AP, Li D, Riddell SR, Park JR, Jensen MC (2017) Intent-to-treat leukemia remission by CD19 CAR T cells of defined formulation and dose in children and young adults. Blood 129(25):3322-3331. https://doi.org/10.1182/blood-2017-02769208

8. Wei GQ, Hu YX, Pu CF, Yu J, Luo Y, Shi JM, Cui Q, Wu WJ, Wang JP, Xiao L, Wu Z, Huang H (2018) CD19 targeted CAR-T therapy versus chemotherapy in re-induction treatment of refractory/relapsed acute lymphoblastic leukemia: results of a case-controlled study. Ann Hematol 97(5):781-789. https://doi. org/10.1007/s00277-018-3246-4

9. Park JH, Riviere I, Gonen M, Wang X, Senechal B, Curran KJ, Sauter C, Wang Y, Santomasso B, Mead E, Roshal M, Maslak P, Davila M, Brentjens RJ, Sadelain M (2018) Long-term follow-up of CD19 CAR therapy in acute lymphoblastic leukemia. N Engl J Med 378(5):449-459. https://doi.org/10.1056/NEJMoa1709919

10. Weng J, Lai P, Qin L, Lai Y, Jiang Z, Luo C, Huang X, Wu S, Shao D, Deng C, Huang L, Lu Z, Zhou M, Zeng L, Chen D, Wang Y, Chen X, Geng S, Robert W, Tang Z, He C, Li P, Du X (2018) A novel generation 1928zT2 CAR T cells induce remission in extramedullary relapse of acute lymphoblastic leukemia. J Hematol Oncol 11(1):25. https://doi.org/10.1186/s13045-0180572-x

11. Cheng Z, Wei RH, Ma QL, Shi L, He F, Shi ZX, Jin T, Xie RL, Wei BF, Chen J, Fang HL, Han XL, Rohrs JA, Bryson P, Liu YR, Li QJ, Zhu B, Wang P (2018) In vivo expansion and antitumor activity of Coinfused CD28-and 4-1BB-engineered CAR-T cells in patients with B cell leukemia. Mol Ther 26(4):976-985. https://doi.org/10. 1016/j.ymthe.2018.01.022

12. Li SQ, Zhang JS, Wang ML, Fu G, Li YY, Pei L, Xiong ZX, Qin DB, Zhang R, Tian XB, Wei ZH, Chen R, Chen XJ, Wan J, Chen J, Wei X, Xu YM, Zhang P, Wang P, Peng X, Yang SN, Shen JJ, Yang Z, Chen JP, Qian C (2018) Treatment of acute lymphoblastic leukaemia with the second generation of CD19 CAR-T containing either CD28 or 4-1BB. Br J Haematol 181(3):360-371. https:// doi.org/10.1111/bjh.15195 
13. Kochenderfer JN, Dudley ME, Feldman SA, Wilson WH, Spaner DE, Maric I, Stetler-Stevenson M, Phan GQ, Hughes MS, Sherry RM, Yang JC, Kammula US, Devillier L, Carpenter R, Nathan DAN, Morgan RA, Laurencot C, Rosenberg SA (2012) B-cell depletion and remissions of malignancy along with cytokine-associated toxicity in a clinical trial of anti-CD19 chimeric-antigen-receptortransduced T cells. Blood 119(12):2709-2720. https://doi.org/10. 1182/blood-2011-10-384388

14. Till BG, Jensen MC, Wang J, Qian X, Gopal AK, Maloney DG, Lindgren CG, Lin Y, Pagel JM, Budde LE, Raubitschek A, Forman SJ, Greenberg PD, Riddell SR, Press OW (2012) CD20-specific adoptive immunotherapy for lymphoma using a chimeric antigen receptor with both CD28 and 4-1BB domains: pilot clinical trial results. Blood 119(17):3940-3950. https://doi.org/10.1182/blood2011-10-387969

15. Wang Y, W-y Z, Q-w H, Liu Y, H-r D, Y-1 G, Bo J, Fan H, Zhang Y, Y-j Z, M-x C, K-c F, Q-s W, X-b F, W-d H (2014) Effective response and delayed toxicities of refractory advanced diffuse large B-cell lymphoma treated by CD20-directed chimeric antigen receptor-modified T cells. Clin Immunol 155(2):160-175. https:// doi.org/10.1016/j.clim.2014.10.002

16. Kochenderfer JN, Dudley ME, Kassim SH, Somerville RPT, Carpenter RO, Stetler-Stevenson M, Yang JC, Phan GQ, Hughes MS, Sherry RM, Raffeld M, Feldman S, Lu L, Li YF, Ngo LT, Goy A, Feldman T, Spaner DE, Wang ML, Chen CC, Kranick SM, Nath A, Nathan D-AN, Morton KE, Toomey MA, Rosenberg SA (2015) Chemotherapy-refractory diffuse large B-cell lymphoma and indolent B-cell malignancies can be effectively treated with autologous $\mathrm{T}$ cells expressing an anti-CD19 chimeric antigen receptor. J Clin Oncol 33(6):540-U531. https://doi.org/10.1200/jco.2014.56.2025

17. Turtle CJ, Hanafi LA, Berger C, Hudecek M, Pender B, Robinson E, Hawkins R, Chaney C, Cherian S, Chen X, Soma L, Wood B, Li D, Heimfeld S, Riddell SR, Maloney DG (2016) Immunotherapy of non-Hodgkin's lymphoma with a defined ratio of CD8+ and CD4+ CD19-specific chimeric antigen receptor-modified T cells. Sci Transl Med 8(355):355ra116. https://doi.org/10.1126/ scitranslmed.aaf 8621

18. Kebriaei P, Singh H, Huls MH, Figliola MJ, Bassett R, Olivares S, Jena B, Dawson MJ, Kumaresan PR, Su SH, Maiti S, Dai JL, Moriarity B, Forget MA, Senyukov V, Orozco A, Liu TT, McCarty J, Jackson RN, Moyes JS, Rondon G, Qazilbash M, Ciurea S, Alousi A, Nieto Y, Rezvani K, Marin D, Popat U, Hosing C, Shpall EJ, Kantarjian H, Keating M, Wierda W, Do KA, Largaespada DA, Lee DA, Hackett PB, Champlin RE, Cooper LJN (2016) Phase I trials using sleeping beauty to generate CD19-specific CAR T cells. J Clin Invest 126(9):3363-3376. https://doi.org/10.1172/jci86721

19. Fitzgerald JC, Weiss SL, Maude SL, Barrett DM, Lacey SF, Melenhorst JJ, Shaw P, Berg RA, June CH, Porter DL, Frey NV, Grupp SA, Teachey DT (2017) Cytokine release syndrome after chimeric antigen receptor $\mathrm{T}$ cell therapy for acute lymphoblastic leukemia. Crit Care Med 45(2):e124-e131. https://doi.org/10. 1097/ccm.0000000000002053

20. Mueller KT, Maude SL, Porter DL, Frey N, Wood P, Han X, Waldron E, Chakraborty A, Awasthi R, Levine BL, Melenhorst JJ, Grupp SA, June CH, Lacey SF (2017) Cellular kinetics of CTL019 in relapsed/refractory B-cell acute lymphoblastic leukemia and chronic lymphocytic leukemia. Blood 130(21):2317-2325. https://doi.org/10.1182/blood-2017-06-786129

21. Neelapu SS, Locke FL, Bartlett NL, Lekakis LJ, Miklos DB, Jacobson CA, Braunschweig I, Oluwole OO, Siddiqi T, Lin Y, Timmerman JM, Stiff PJ, Friedberg JW, Flinn IW, Goy A, Hill BT, Smith MR, Deol A, Farooq U, McSweeney P, Munoz J, Avivi I, Castro JE, Westin JR, Chavez JC, Ghobadi A, Komanduri KV, Levy R, Jacobsen ED, Witzig TE, Reagan P, Bot A, Rossi J, Navale L, Jiang Y, Aycock J, Elias M, Chang D,
Wiezorek J, Go WY (2017) Axicabtagene Ciloleucel CAR T-cell therapy in refractory large B-cell lymphoma. N Engl J Med 377(26):2531-2544. https://doi.org/10.1056/NEJMoa1707447

22. Porter DL, Hwang W-T, Frey NV, Lacey SF, Shaw PA, Loren AW, Bagg A, Marcucci KT, Shen A, Gonzalez V, Ambrose D, Grupp SA, Chew A, Zheng Z, Milone MC, Levine BL, Melenhorst JJ, June $\mathrm{CH}$ (2015) Chimeric antigen receptor T cells persist and induce sustained remissions in relapsed refractory chronic lymphocytic leukemia. Sci Transl Med 7(303):303ra139. https://doi.org/10. 1126/scitranslmed.aac5415

23. Brudno JN, Kochenderfer JN (2016) Toxicities of chimeric antigen receptor T cells: recognition and management. Blood 127(26): 3321-3330. https://doi.org/10.1182/blood-2016-04-703751

24. Teachey DT, Lacey SF, Shaw PA, Melenhorst JJ, Maude SL, Frey N, Pequignot E, Gonzalez VE, Chen F, Finklestein J, Barrett DM, Weiss SL, Fitzgerald JC, Berg RA, Aplenc R, Callahan C, Rheingold SR, Zheng Z, Rose-John S, White JC, Nazimuddin F, Wertheim G, Levine BL, June CH, Porter DL, Grupp SA (2016) Identification of predictive biomarkers for cytokine release syndrome after chimeric antigen receptor T-cell therapy for acute lymphoblastic leukemia. Cancer Discov 6(6):664-679. https://doi.org/ 10.1158/2159-8290.cd-16-0040

25. Hu Y, Sun J, Wu Z, Yu J, Cui Q, Pu C, Liang B, Luo Y, Shi J, Jin A, Xiao L, Huang H (2016) Predominant cerebral cytokine release syndrome in CD19-directed chimeric antigen receptor-modified $\mathrm{T}$ cell therapy. J Hematol Oncol 9:70. https://doi.org/10.1186/s13045016-0299-5

26. Mei H, Jiang H, Wu Y, Guo T, Xia L, Jin R, Hu Y (2018) Neurological toxicities and coagulation disorders in the cytokine release syndrome during CAR-T therapy. Br J Haematol 181(5): 689-692. https://doi.org/10.1111/bjh.14680

27. Neelapu SS, Tummala S, Kebriaei P, Wierda W, Gutierrez C, Locke FL, Komanduri KV, Lin Y, Jain N, Daver N, Westin J, Gulbis AM, Loghin ME, de Groot JF, Adkins S, Davis SE, Rezvani K, Hwu P, Shpall EJ (2018) Chimeric antigen receptor T-cell therapy - assessment and management of toxicities. Nat Rev Clin Oncol 15(1):4762. https://doi.org/10.1038/nrclinonc.2017.148

28. Kalos M, Levine BL, Porter DL, Katz S, Grupp SA, Bagg A, June $\mathrm{CH}$ (2011) T cells with chimeric antigen receptors have potent antitumor effects and can establish memory in patients with advanced leukemia. Sci Transl Med 3(95):95ra73. https://doi.org/10. 1126/scitranslmed.3002842

29. Tang XY, Sun Y, Zhang A, Hu GL, Cao W, Wang DH, Zhang B, Chen $\mathrm{H}$ (2016) Third-generation CD28/4-1BB chimeric antigen receptor $\mathrm{T}$ cells for chemotherapy relapsed or refractory acute lymphoblastic leukaemia: a non-randomised, open-label phase I trial protocol. BMJ Open 6(12):e013904. https://doi.org/10.1136/ bmjopen-2016-013904

30. Hill JA, Li D, Hay KA, Green ML, Cherian S, Chen XY, Riddell SR, Maloney DG, Boeckh M, Turtle CJ (2018) Infectious complications of CD19-targeted chimeric antigen receptor-modified T-cell immunotherapy. Blood 131(1):121-130. https://doi.org/10.1182/ blood-2017-07-793760

31. Park JH, Romero FA, Taur Y, Sadelain M, Brentjens RJ, Hohl TM, Seo SK (2018) Cytokine release syndrome grade is a predictive marker for infections in relapsed or refractory B-cell all patients treated with CAR T cells. Clin Infect Dis 67:533-540. https://doi. org/10.1093/cid/ciy152

32. Lee DW, Gardner R, Porter DL, Louis CU, Ahmed N, Jensen M, Grupp SA, Mackall CL (2014) Current concepts in the diagnosis and management of cytokine release syndrome. Blood 124(2):188195. https://doi.org/10.1182/blood-2014-05-552729

33. Wang M, Kou H, Deng J, Wang H, Guo T, Mei H, Hu Y (2015) Retrospective evaluation of new Chinese diagnostic scoring system for disseminated intravascular coagulation. PLoS One 10(6): e0129170. https://doi.org/10.1371/journal.pone.0129170 
34. Luo L, Wu Y, Niu T, Han Y, Feng Y, Ding Q, Huang R, Zhang X, Feng J, Hou M, Peng J, Li Y, Zhou Y, Su L, Yang L, Zhou Z, Xue F, Gu J, Zhu T, Wang X, Deng J, Mei H, Hu Y (2018) A multicenter, prospective evaluation of the Chinese Society of Thrombosis and Hemostasis Scoring System for disseminated intravascular coagulation. Thromb Res 173:131-140. https://doi.org/10.1016/j. thromres.2018.11.022

35. Wu YY, Luo LL, Niu T, Han Y, Feng Y, Ding QL, Huang RB, Zhang XH, Feng JM, Hou M, Peng J, Li Y, Zhou YH, Su L, Yang LH, Zhou ZP, Xue F, Gu J, Zhu TN, Wang XM, Deng J, Mei H, Hu Y (2017) Evaluation of the new Chinese disseminated intravascular coagulation scoring system in critically ill patients: a multicenter prospective study. Sci Rep 7(8):9057. https://doi.org/ 10.1038/s41598-017-09190-5

36. Goldberger A, Middleton KA, Oliver JA, Paddock C, Yan H-C, Delisser HM, Albelda SM, Newman PJ (1994) Biosynthesis and processing of the cell adhesion molecule PECAM-1 includes production of a soluble form. J Biol Chem 269(25):17183-17191

37. Privratsky JR, Newman PJ (2014) PECAM-1: regulator of endothelial junctional integrity. Cell Tissue Res 355(3):607-619. https:// doi.org/10.1007/s00441-013-1779-3

38. Duan J, Liang S, Yu Y, Li Y, Wang L, Wu Z, Chen Y, Miller MR, Sun $Z$ (2018) Inflammation-coagulation response and thrombotic effects induced by silica nanoparticles in zebrafish embryos. Nanotoxicology 12(5):470-484. https://doi.org/10.1080/ 17435390.2018 .1461267

39. Gust J, Hay KA, Hanafi LA, Li D, Myerson D, Gonzalez-Cuyar LF, Yeung C, Liles WC, Wurfel M, Lopez JA, Chen JM, Chung D, Harju-Baker S, Tzpolat T, Fink KR, Riddell SR, Maloney DG, Turtle CJ (2017) Endothelial activation and blood-brain barrier disruption in neurotoxicity after adoptive immunotherapy with CD19 CAR-T cells. Cancer Discov 7(12):1404-1419. https://doi.org/10. 1158/2159-8290.cd-17-0698
40. Hay KA, Hanafi LA, Li D, Gust J, Liles WC, Wurfel MM, Lopez JA, Chen J, Chung D, Harju-Baker S, Cherian S, Chen X, Riddell SR, Maloney DG, Turtle CJ (2017) Kinetics and biomarkers of severe cytokine release syndrome after CD19 chimeric antigen receptor-modified T-cell therapy. Blood 130(21):2295-2306. https://doi.org/10.1182/blood-2017-06-793141

41. Taylor FB Jr, Chang A, Ruf W, Morrissey JH, Hinshaw L, Catlett R, Blick K, Edgington TS (1991) Lethal E. coli septic shock is prevented by blocking tissue factor with monoclonal antibody. Circ Shock 33(3):127-134

42. Levi M, Ten Cate H, Bauer KA, Van Der Poll T, Edgington TS, Buller HR, Van Deventer SJH, Hack CE, Ten Cate JW, Rosenberg RD (1994) Inhibition of endotoxin-induced activation of coagulation and fibrinolysis by pentoxifylline or by a monoclonal antitissue factor antibody in chimpanzees. J Clin Invest 93(1):114 120. https://doi.org/10.1172/jci116934

43. Maas M, Stapleton M, Bergom C, Mattson DL, Newman DK, Newman PJ (2005) Endothelial cell PECAM-1 confers protection against endotoxic shock. Am J Phys Heart Circ Phys 288(1):H159H164. https://doi.org/10.1152/ajpheart.00500.2004

44. Porter D, Frey N, Wood PA, Weng YQ, Grupp SA (2018) Grading of cytokine release syndrome associated with the CAR T cell therapy tisagenlecleucel. J Hematol Oncol 11:12. https://doi.org/10. 1186/s13045-018-0571-y

45. Gould TJ, Lysov Z, Liaw PC (2015) Extracellular DNA and histones: double-edged swords in immunothrombosis. J Thromb Haemost 13:S82-S91. https://doi.org/10.1111/jth.12977

Publisher's note Springer Nature remains neutral with regard to jurisdictional claims in published maps and institutional affiliations. 